\title{
Bone Radionuclide Imaging, Quantitation and Bone Densitometry
}

\author{
Glen M. Blake and Ignac Fogelman
}

\subsection{Radionuclide Imaging of Bone}

It was the development of the cyclotron by Ernest Lawrence at Berkeley during the 1930s that first made radionuclides available in the quantity and variety to allow investigations of their medical use. Lawrence's brother John, who was a physician, directed the first clinical studies, which included an investigation by Charles Pecher of the treatment of metastatic bone disease with ${ }^{89} \mathrm{Sr}$ [1]. An important finding made at Berkeley was the discovery of ${ }^{99 \mathrm{~m}} \mathrm{Tc}$ in 1938 by Segrè and Seaborg in a sample of irradiated molybdenum [2]. But further developments had to await the end of the war.

Since calcium has no radioisotopes suitable for imaging, the next obvious element to exploit was strontium. In 1959 Bauer and Wendeberg [3] described the first clinical study with ${ }^{85} \mathrm{Sr}\left(\mathrm{E} \gamma=514 \mathrm{keV} ; \mathrm{T}_{1 / 2}=65\right.$ days $)$, but its use was limited by the long half-life and consequent high radiation dose. In 1964 Charkes, Sklaroff and Bierly [4] described skeletal scintigraphy with ${ }^{87 \mathrm{~m}} \mathrm{Sr}\left(\mathrm{E} \gamma=388 \mathrm{keV} ; \mathrm{T}_{1 / 2}=2.8 \mathrm{~h}\right)$, a short half-life isomeric radionuclide conveniently available from a generator. ${ }^{87 \mathrm{~m}} \mathrm{Sr}$ was the bone agent used in Sheffield where one of us (GB) started work in 1972. Its disadvantage was the high renal tubular reabsorption of strontium, which combined with the short half-life led to indistinct images with a high soft tissue background (Fig. 15.1).

A much superior agent, ${ }^{18} \mathrm{~F}$-fluoride, was described by Blau, Nagler and Bender in 1962 [5], but its use required an onsite cyclotron which was available in very few centres. By the early 1970s the situation was ripe for the introduction of ${ }^{99 \mathrm{~m}} \mathrm{Tc}$ labelled bone radiopharmaceuticals.

G.M. Blake $(\bowtie) \bullet$ I. Fogelman

Department of Nuclear Medicine, Guy's Campus, King's College London,

London SE1 9RT, UK 
Fig. 15.1 Colour ribbon printout of an ${ }^{87 \mathrm{~m}} \mathrm{Sr}$ bone scan performed on a rectilinear scanner (Reproduced with permission from Kemp et al. [20])

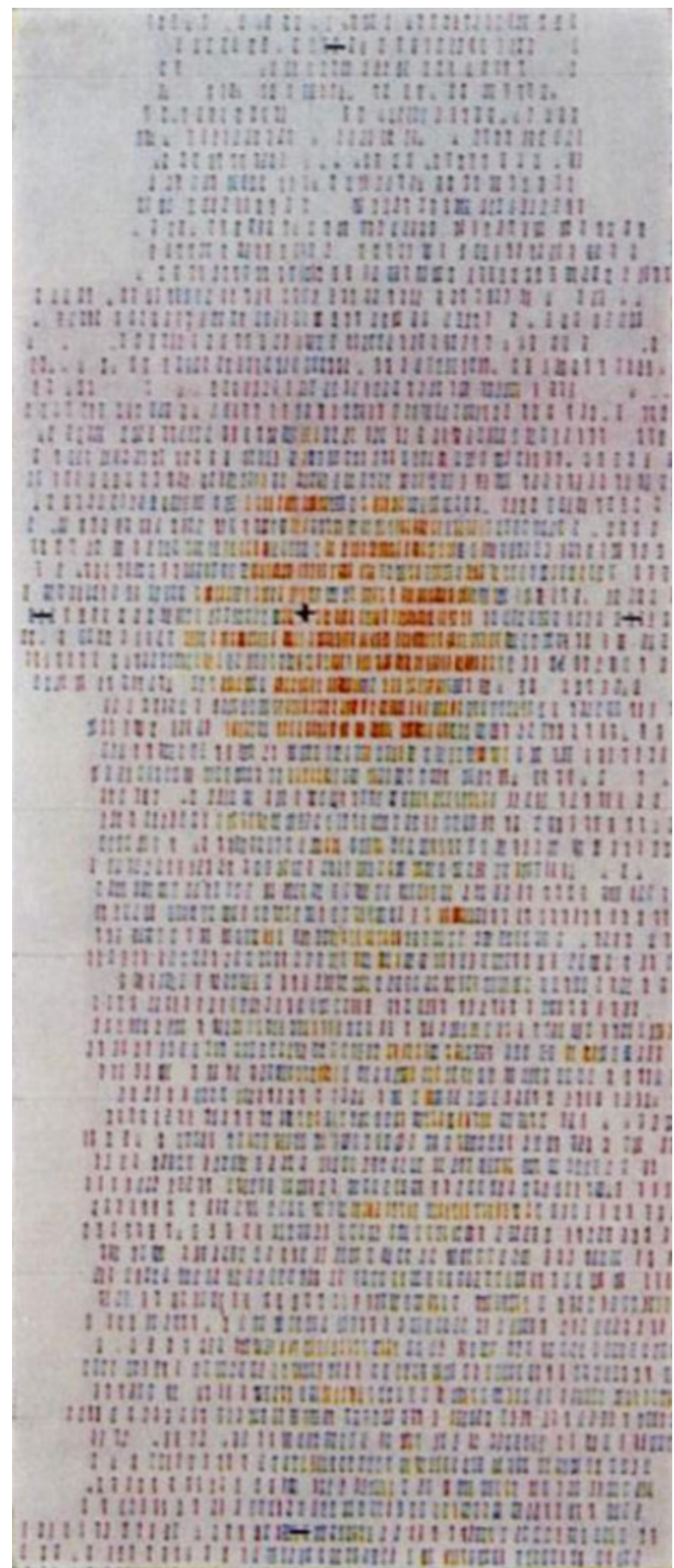




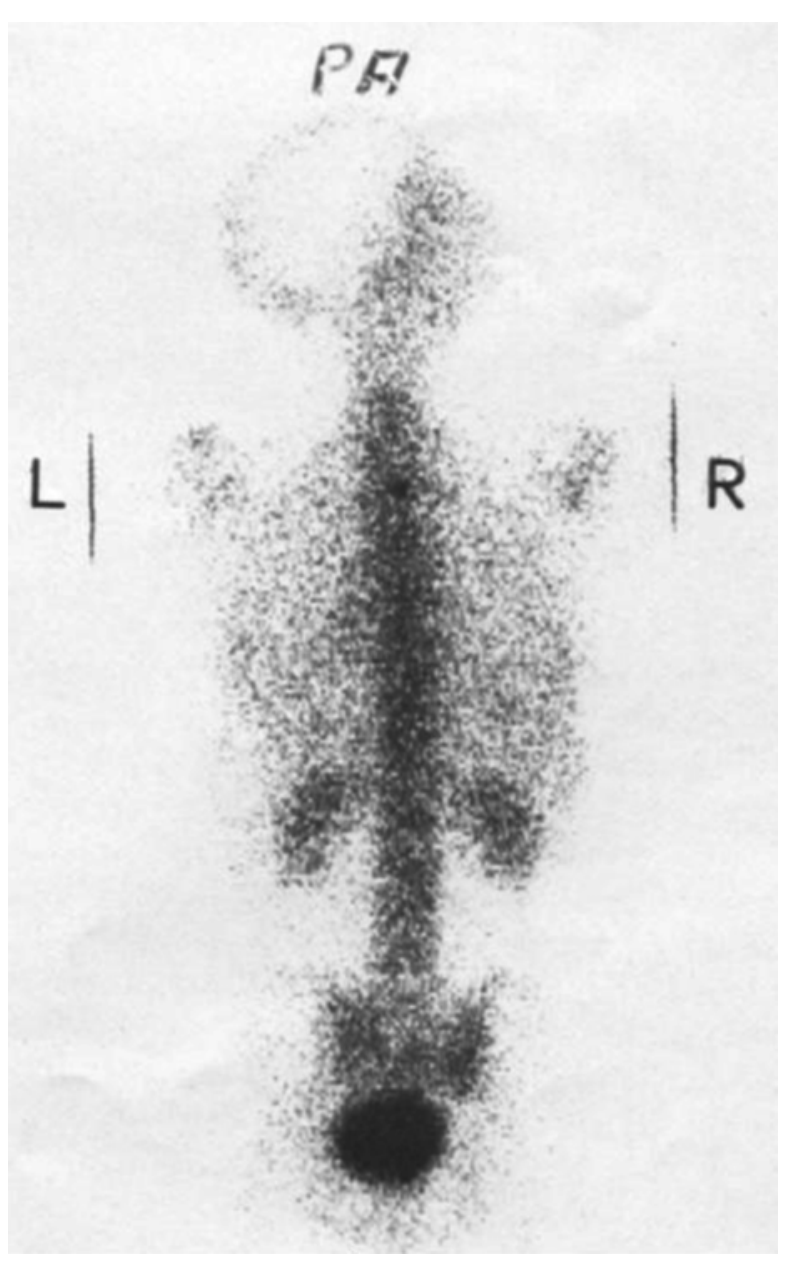

Fig. 15.2 Black and white film scintiscan from a rectilinear scanner showing a ${ }^{99 \mathrm{~m}} \mathrm{Tc}$ polyphosphate bone scan in a patient with no abnormalities (Reproduced with permission from Redman and Turley [21])

Interest in ${ }^{99 \mathrm{~m}} \mathrm{Tc}$ for Nuclear Medicine imaging began in the early 1960s following the development of the ${ }^{99 \mathrm{~m}} \mathrm{Tc}$ generator by Tucker and Greene at the Brookhaven laboratory [6]. The first technetium labelled bone agent, ${ }^{99 \mathrm{~m}} \mathrm{Tc}$-polyphosphate, was described by Subramanian and McAfee [7] in 1971 (Fig. 15.2), and so radical was the improvement in image quality that by $1973^{87 \mathrm{~m}} \mathrm{Sr}$ had fallen out of use.

In 1975 Subramanian described a superior agent, ${ }^{99 m} \mathrm{Tc}-$ methylene diphosphonate [8], and with the introduction of the wide-field-of-view gamma camera and the replacement of spot views with whole-body scans the Nuclear Medicine bone scan took its modern form.

Recent years have seen a further change in the choice of optimum tracer as the wider availability of PET scanners has brought renewed interest in ${ }^{18} \mathrm{~F}$-fluoride. ${ }^{18} \mathrm{~F}$ 
is superior to ${ }^{99 \mathrm{~m}} \mathrm{Tc}-\mathrm{MDP}$ for skeletal imaging because of its higher plasma clearance to bone and absence of protein binding, both factors that lead to improved bone to soft tissue uptake. In addition PET is a superior imaging technique with higher spatial resolution and sensitivity compared with the gamma camera. The ${ }^{99 \mathrm{~m}} \mathrm{Tc}$ MDP bone scan is an old and trusted friend that continues to perform with some distinction, but it is apparent that we can do significantly better with ${ }^{18} \mathrm{~F}$. As PET scanners become more widely available there appears to be a compelling case for the introduction of ${ }^{18} \mathrm{~F}$-fluoride as the preferred agent [9].

\subsection{Quantitation of Bone Tracer Kinetics}

There is a large early literature describing non-imaging studies of bone tracer kinetics using nuclides such as ${ }^{45} \mathrm{Ca}\left(\mathrm{T}_{1 / 2}=163\right.$ days $),{ }^{47} \mathrm{Ca}\left(\mathrm{T}_{1 / 2}=4.5\right.$ days $)$ and ${ }^{85} \mathrm{Sr}$ $\left(\mathrm{T}_{1 / 2}=65\right.$ days). Imaging studies using short half-life tracers such as ${ }^{99 \mathrm{~m}} \mathrm{Tc}-\mathrm{MDP}$ and ${ }^{18} \mathrm{~F}$-fluoride provide more restricted information, but have the advantage of allowing regional as well as whole skeleton measurements. Perhaps the most widely known bone quantitation method using an imaging tracer is the $24-\mathrm{h}{ }^{99 \mathrm{~m}} \mathrm{Tc}$ MDP whole-body retention test described by Fogelman in the late 1970s while working at the Glasgow Royal Infirmary [10]. In this test the patient is injected with a tracer amount $(\sim 1 \mathrm{MBq})$ of ${ }^{99 \mathrm{~m}} \mathrm{Tc}-\mathrm{MDP}$ and has a head-to-foot measurement in a shadow shield whole-body counter. The measurement is repeated $24 \mathrm{~h}$ later and, on the assumption the tracer is either cleared to bone or excreted through the kidneys, the counts are corrected for background and radioactive decay and the retention of ${ }^{99 \mathrm{~m}} \mathrm{Tc}-\mathrm{MDP}$ calculated. With the lack today of whole-body counter facilities, Brenner described a gamma camera measurement of whole-skeleton uptake based on whole-body scans acquired at $3 \mathrm{~min}$ and $6 \mathrm{~h}$ after injection [11]. By drawing a large region of interest over the adductor muscles the percentage of tracer still in soft tissue at $6 \mathrm{~h}$ is inferred and subtracted from the whole body retention to estimate the amount in bone.

A new method of using gamma camera scans to perform whole-skeleton and regional measurements of ${ }^{99 \mathrm{~m}} \mathrm{Tc}-\mathrm{MDP}$ bone plasma clearance (analogous to the measurement of renal function using GFR) was developed by Amelia Moore and colleagues at Guy's Hospital [12]. Fast ( $10 \mathrm{~min})$ anterior and posterior whole-body scans are performed at $10 \mathrm{~min}, 1,2,3$ and $4 \mathrm{~h}$ after injection, and blood samples taken at 5, 20, 60, 120, 180 and $240 \mathrm{~min}$. The latter are centrifuged by ultrafiltration to determine the plasma concentration of free (non-protein bound) ${ }^{99 \mathrm{~m}} \mathrm{Tc}-\mathrm{MDP}$ and the Patlak method used to determine whole-skeleton and regional (skull, spine, pelvis, arms, legs) bone plasma clearance. The method was used by Moore to investigate the effect of teriparatide on the bone scan in postmenopausal women treated for osteoporosis [13].

Just as PET imaging with ${ }^{18} \mathrm{~F}$-fluoride is superior to the ${ }^{99 \mathrm{~m}} \mathrm{Tc}-\mathrm{MDP}$ gamma camera scan, the same is true for bone quantitation. Hawkins et al. [14] described a method of measuring ${ }^{18} \mathrm{~F}$ bone plasma clearance in the lumbar spine (units: $\mathrm{mL} \mathrm{min}{ }^{-1} \mathrm{~mL}^{-1}$ ) by applying compartmental modelling to a 60-min dynamic PET scan with arterial sampling of the plasma curve. The method was simplified by Michelle Frost and 
colleagues at Guy's Hospital [15] so that from a series of venous blood samples and bed positions regional plasma clearance could be measured across the entire skeleton with a single injection of tracer. With the ability of ${ }^{18} \mathrm{~F}$ PET scans to make measurements at the hip, the most important fracture site, we believe this is the best method for studying the effect of osteoporosis treatments on regional bone metabolism.

\subsection{Bone Densitometry}

The first bone densitometer based on photon absorptiometry was described by Cameron and Sorenson in 1963 [16] and used the $27 \mathrm{keV}$ radiation from a ${ }^{125} \mathrm{I}$ source to measure bone mineral content in the radius, a method known as single photon absorptiometry (SPA). Because the beam contained photons with just a single energy it was necessary to place the patient's forearm in a water bath to simulate a constant thickness of soft tissue across the wrist.

During the 1970s Medical Physics groups at the University of Wisconsin and other centres pioneered the development of dual photon absorptiometry (DPA) using a rectilinear scanning device with a ${ }^{153} \mathrm{Gd}$ source with emissions at 44 and $100 \mathrm{keV}$ [17]. Unlike SPA, these devices were able to scan the spine and hip. By the early 1980s several companies were manufacturing DPA scanners and in 1982 Frans Verlaan, founder of Vertec Scientific, organised a conference in London for those interested in the new technology that was attended by many from the Nuclear Medicine community. In some UK centres medical physicists such as Victor Poll in Southampton built their own systems from old rectilinear scanners. Because of the use of a radioactive source, the DPA devices were largely confined to Nuclear Medicine Departments with experience in the safe handling of radionuclides.

The limitation of DPA was that it is impossible to contain sufficient radioactivity in a small enough volume to achieve both the necessary count rate and adequate spatial resolution. In 1988 in the recently opened Guy's Osteoporosis Unit patient appointment times for the Novo BMC-LAB 22a DPA system were $1 \mathrm{~h}$ long, as it took $30 \mathrm{~min}$ to scan and analyse the spine, and a similar time for the hip (Fig. 15.3a, b).

In the same year bone densitometry was revolutionised when Jay Stein, founder of Hologic, replaced the ${ }^{153} \mathrm{Gd}$ source with an X-ray tube and produced the first dualenergy X-ray absorptiometry (DXA) system. This provided an improvement in scan quality for bone densitometry just as radical as ${ }^{99 \mathrm{~m}} \mathrm{Tc}-\mathrm{MDP}$ had for the radionuclide bone scan a decade earlier. Overnight the market for DPA systems was dead!

With a rapidly growing number of centres offering a DXA service it was necessary to devise clearer ways of reporting scans. In 1994 a group of physicians led by John Kanis recommended that DXA scans should be interpreted using T-scores defined as the BMD measurement expressed in standard deviation units relative to a population of healthy young adults, with osteoporosis defined as a T-score of less than -2.5 at the spine, hip or forearm [18]. This simple definition caught the imagination of clinicians and ever since the T-score has been a cornerstone of DXA scan reporting. But it ignores the fact that fracture risk increases progressively with 


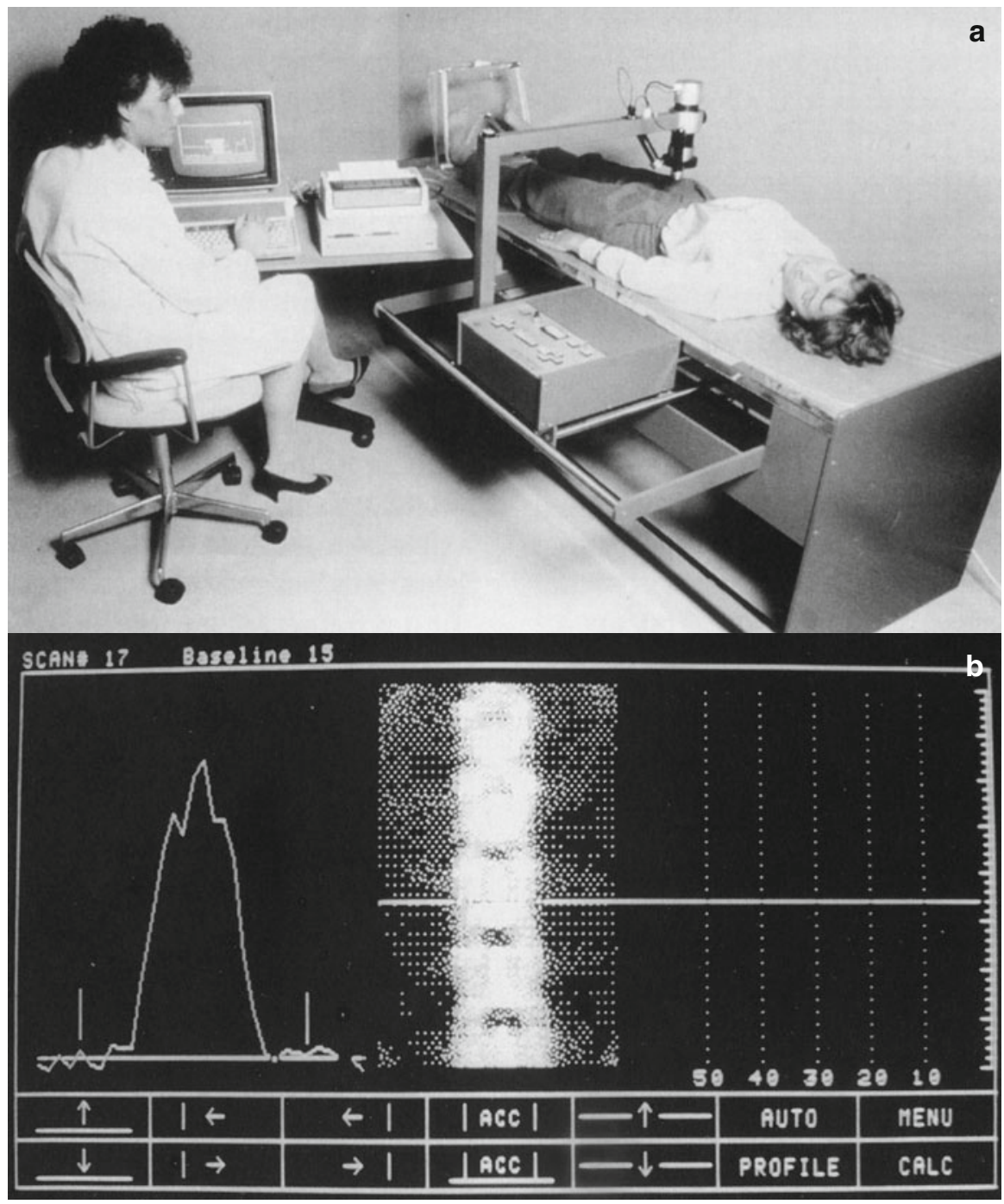

Fig. 15.3 (a) A Novo BMC-LAB 22a DPA scanner as used in the mid-1980s. (b) A lumbar spine DPA scan being analysed on a Novo BMC-LAB 22a system. Note the facility for the line-by-line adjustment of the soft tissue reference baseline on the left hand side of the image

diminishing BMD and does not take into account factors such as age and previous fractures in evaluating risk. In 2008 a collaboration under John Kanis placed the interpretation of DXA scans on a more secure footing by launching the FRAX website [19] where a clinician can enter details of a patient's hip T-score and clinical risk factors and obtain an estimate of their 10-year risk of fracture. 
Open Access This chapter is distributed under the terms of the Creative Commons AttributionNoncommercial 2.5 License (http://creativecommons.org/licenses/by-nc/2.5/) which permits any noncommercial use, distribution, and reproduction in any medium, provided the original author(s) and source are credited.

The images or other third party material in this chapter are included in the work's Creative Commons license, unless indicated otherwise in the credit line; if such material is not included in the work's Creative Commons license and the respective action is not permitted by statutory regulation, users will need to obtain permission from the license holder to duplicate, adapt or reproduce the material.

\section{References}

1. Pecher C. Biological investigations with radioactive calcium and strontium: preliminary report on the use of radioactive strontium in the treatment of metastatic bone cancer. Univ Calif Publ Pharmacol. 1942;2:117-49.

2. Segrè E, Seaborg GT. Nuclear isomerism in element 43. Phys Rev. 1938;54:772.

3. Bauer GC, Wendeberg B. External counting of $\mathrm{Ca}^{47}$ and $\mathrm{Sr}^{85}$ in studies of localised skeletal lesions in man. J Bone Joint Surg Br. 1959;41-B:558-80.

4. Charkes ND, Sklaroff DM, Bierly J. Detection of metastatic cancer to bone by scintiscanning with strontium-87 m. Am J Roentgenol Radium Ther Nucl Med. 1964;91:1121-7.

5. Blau M, Nagler W, Bender MA. Fluorine-18: a new isotope for bone scanning. J Nucl Med. 1962;3:332-4.

6. Richards P. Technetium-99m: the early days. 1989. Available at: http://www.osti.gov/scitech/ servlets/purl/5612212/. Accessed 3 Sept 2015.

7. Subramanian G, McAfee JG. A new complex of ${ }^{99 \mathrm{~m}} \mathrm{Tc}$ for skeletal imaging. Radiology. 1971;99:192-6.

8. Subramanian G, McAfee JG, Blair RJ, Kallfelz FA, Thomas FD. Technetium-99m-methylene diphosphonate - a superior agent for skeletal imaging: comparison with other technetium complexes. J Nucl Med. 1975;16:744-55.

9. Fogelman I, Blake GM, Cook GJ. The isotope bone scan: we can do better. Eur J Nucl Med Mol Imaging. 2013;40:1139-40.

10. Fogelman I, Bessent RG, Turner JG, Citrin DL, Boyle IT, Greig WR. The use of whole-body retention of Tc-99m diphosphonate in the diagnosis of metabolic bone disease. J Nucl Med. 1978;19:270-5.

11. Brenner W, Bohuslavizki KH, Sieweke N, Tinnemeyer S, Clausen M, Henze E. Quantification of diphosphonate uptake based on conventional bone scanning. Eur $\mathrm{J}$ Nucl Med. 1997;24:1284-90.

12. Moore AE, Blake GM, Fogelman I. Quantitative measurements of bone remodeling using ${ }^{99 m}$ Tc-methylene diphosphonate bone scans and blood sampling. J Nucl Med. 2008;49:375-82.

13. Moore AE, Blake GM, Taylor KA, Ruff VA, Rana AE, Wan X, Fogelman I. Changes observed in radionuclide bone scans during and after teriparatide treatment for osteoporosis. Eur J Nucl Med Mol Imaging. 2012;39:326-36.

14. Hawkins RA, Choi Y, Huang SC, Hoh CK, Dahlbom M, Schiepers C, Satyamurthy N, Barrio JR, Phelps ME. Evaluation of the skeletal kinetics of fluorine-18-fluoride ion with PET. J Nucl Med. 1992;33:633-42.

15. Frost ML, Moore AE, Siddique M, Blake GM, Laurent D, Borah B, Schramm U, Valentin MA, Pellas TC, Marsden PK, Schleyer PJ, Fogelman I. ${ }^{18} \mathrm{~F}$-fluoride PET as a noninvasive imaging biomarker for determining treatment efficacy of bone active agents at the hip: a prospective, randomized, controlled clinical study. J Bone Miner Res. 2013;28:1337-47.

16. Cameron JR, Sorenson J. Measurement of bone mineral in vivo: an improved method. Science. $1963 ; 142: 230-2$. 
17. Wilson CR, Madsen M. Dichromatic absorptiometry of vertebral bone mineral content. Invest Radiol. 1977;12:180-4.

18. WHO technical report series 843: assessment of fracture risk and its application to screening for postmenopausal osteoporosis. Geneva: World Health Organization; 1994.

19. World Health Organization Collaborating Centre for Metabolic Bone Diseases. FRAX® WHO fracture risk assessment tool web version 3.9, released 17 Oct 2014. Available at: http://www. shef.ac.uk/FRAX. Accessed 3 Sept 2015.

20. Kemp HBS, Johns DL, McAlister J, Goodlee JN. The role of fluorine-18 and strontium- $87 \mathrm{~m}$ scintigraphy in the management of infective spondylitis. J Bone Joint Surg. 1973;55:301-11.

21. Redman JF, Turley JT. Technetium polyphosphate bone scans in carcinoma of the prostate. Urology. 1973;1:218-20. 


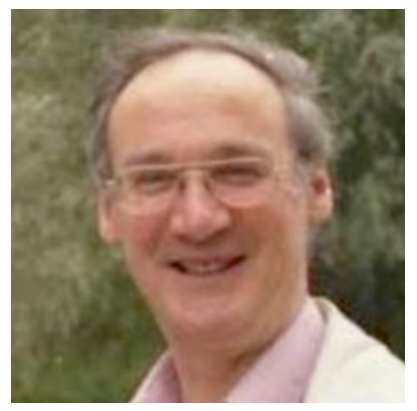

Glen M. Blake I was born in Walthamstow in East London and was fortunate to benefit from the 11-Plus exam, going to Chigwell School in Essex. I won an open scholarship to study Physics at Oxford and came out with the top first in my year group. After that I did a PhD in the Radio Astronomy group at the Cavendish Laboratory under Martin Ryle. My interest in Medical Physics developed from a fellow research student, Lawrence Oldfield, who had just returned from a year working in Canada in radiotherapy. My first post in the NHS was in Sheffield where the Medical Physics Department was led by Harold Miller. Harold had been a student of James Chadwick in 1932, the year that Chadwick discovered the neutron. I worked in the Isotope Unit at the Sheffield Royal Infirmary, and later at the Hallamshire Hospital when it opened in 1978. There I worked with John Kanis on a grant proposal to purchase one of the early DPA bone density scanners for research projects in Sheffield. In 1984 I moved to the Nuclear Medicine Department at Southampton under Duncan Ackery where I widened my experience and was involved with projects that included the use of ${ }^{89} \mathrm{Sr}$ to treat metastatic bone disease. In 1989 I moved to the Nuclear Medicine Department at Guy's Hospital under Ignac Fogelman. Here I had the opportunity to take up bone densitometry again in the recently opened Osteoporosis Unit. At Guy's I became more heavily involved with teaching and supervising research students, and in 2003 I moved from the NHS to work for King's College London, becoming Professor of Osteoporosis in 2012. 


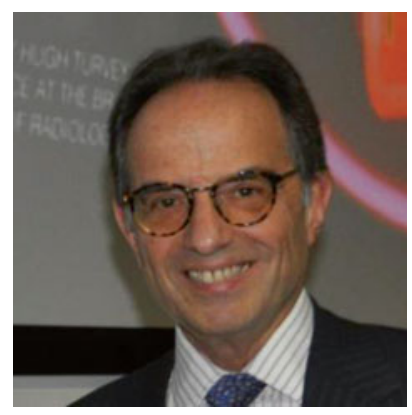

Ignac Fogelman Professor Ignac Fogelman is currently Professor of Nuclear Medicine at King's College London and Honorary Consultant Physician at Guy's and St Thomas' NHS Trust and Director of the Osteoporosis Screening and Research Unit, Guy's Hospital. Professor Fogelman did his medical training in the Professorial Department of Medicine at the Glasgow Royal Infirmary where he developed his interest in metabolic bone disease working with Dr Iain Boyle and Dr Rodney Bessent. At that time Nuclear Medicine in Glasgow came under the wing of the Department of Medicine, and the newly available ${ }^{99 \mathrm{~m}} \mathrm{Tc}$-diphosphonate imaging agents proved a useful means of investigating metabolic bone disease, leading to the first of over 400 publications and the completion of his MD. His appointment as Consultant Physician in the Nuclear Medicine Department at Guy's Hospital in 1983 gave further opportunities to develop his interests in bone. In 1988 he instigated the first osteoporosis screening service in the UK, initially using a DPA scanner and later one of the first DXA systems. In 1996 he became Professor of Nuclear Medicine. He has written or edited 15 books and supervised $17 \mathrm{PhD} / \mathrm{MD}$ students. $\mathrm{He}$ is a former board member and trustee of the National Osteoporosis Society and was previously chairman of its Bone Densitometry Forum. Professor Fogelman is currently chairman of the board of examiners for the MSc in Nuclear Medicine at King's College, which provides the only recognised training programme for Nuclear Medicine in the UK. 